\title{
A Series-Parallel Hydraulic Hybrid Mini-Excavator with Displacement Controlled Actuators
}

\author{
Rohit Hippalgaonkar ${ }^{*}$ and Monika Ivantysynova ${ }^{+}$ \\ ${ }^{+}$Department of Agricultural \& Biological Engineering, Purdue University, West Lafayette, IN/ USA \\ E-mail: rohit@purdue.edu, mivantys@purdue.edu \\ *School of Mechanical Engineering, Purdue University, West Lafayette, IN/ USA
}

\begin{abstract}
A displacement-controlled (DC) prototype mini-excavator built at the Maha Fluid Power Research Center at Purdue University, had previously demonstrated $40 \%$ fuel savings over a standard mini-excavator with load-sensing architecture, in independent side-by-side testing. A DC series-parallel (DC S-P) hydraulic hybrid architecture has since been conceptualized where the braking energy of the swing can be stored in an accumulator. This architecture promises further efficiency gains over the DC architecture by taking advantage of four-quadrant operation enabled by DC actuation, swing kinetic energy storage capability, and enables 50\% reduced engine power, through load-leveling and power management, while exploiting the cyclical nature of excavator work cycles. In simulation, feasibility studies for the DC S-P hybrid excavator with reduced engine power, showed $51 \%$ fuel savings over the standard excavator without loss of performance for an expert truck-loading cycle. Conservative power management was used for these studies, with the downsized engine operated efficiently at a single point (maximum governed speed and torque).

This work will focus on: a) the high-fidelity co-simulation model used to model dynamic behavior and evaluate various power management strategies, b) working hydraulic schematics for the series-hybrid swing drive, c) the controller in use on the prototype, and d) measurements for proof-of-concept.
\end{abstract}

Keywords: DC actuation, hydraulic hybrid, multi-actuator machines, engine management and downsizing, secondary-controlled swing motor.

\section{Background}

Rising fuel costs, more stringent emission restrictions and increasing use of electronic controls and sensors have recently accelerated research and development of efficient hydraulic actuation technologies. In multi-actuator machines, DC actuation is a relatively recent technology that eliminates the use of throttling valves that are used in the current standard valve-controlled versions of these machines.

In DC actuation, one variable displacement over-center hydraulic unit is used for each actuator to control the actuator motion ([1]). For differential cylinders, pilotoperated check valves are used to ensure balancing the unequal cylinder flow. The DC prototype mini-excavator (5t) built at the Maha Fluid Power Research Center at Purdue University uses four variable displacement pumps to power the four main actuators of the excavator, the boom, arm, bucket and swing drive. Switching valves allow switching of all four pumps to power the remaining four actuators, also utilizing the efficient displacement controlled actuation concept.

Simulations were performed using detailed, dynamic cosimulation models of both the standard, load-sensing (LS) architecture as well as the DC architecture for the 5-t excavator system [2], [3]). It was found that throttling losses accounted for $50 \%$ of the energy consumption in the LS machine, and that the DC system could provide $40 \%$ fuel savings over the LS system. A prototype DC excavator was built at the Maha Fluid Power Research Center, and this validated the prediction made using simulations, during independent, side-by-side testing with an LS excavator ([4], [5]) at a Caterpillar testing facility.

A novel hybrid hydraulic architecture ([6]) builds on the success of the DC prototype excavator, by enabling storage (and reuse) of braking energy of the cabin in a high-pressure hydraulic accumulator, via a series hybrid swing drive as shown in Figure 1.1.

The DC S-P architecture retains the circuits for the linear actuators in the prototype DC excavator. The DC S-P hybrid enables $50 \%$ engine downsizing through appropriate power 
management, relying on typical cyclical operation of excavators, and in the process further fuel savings over the

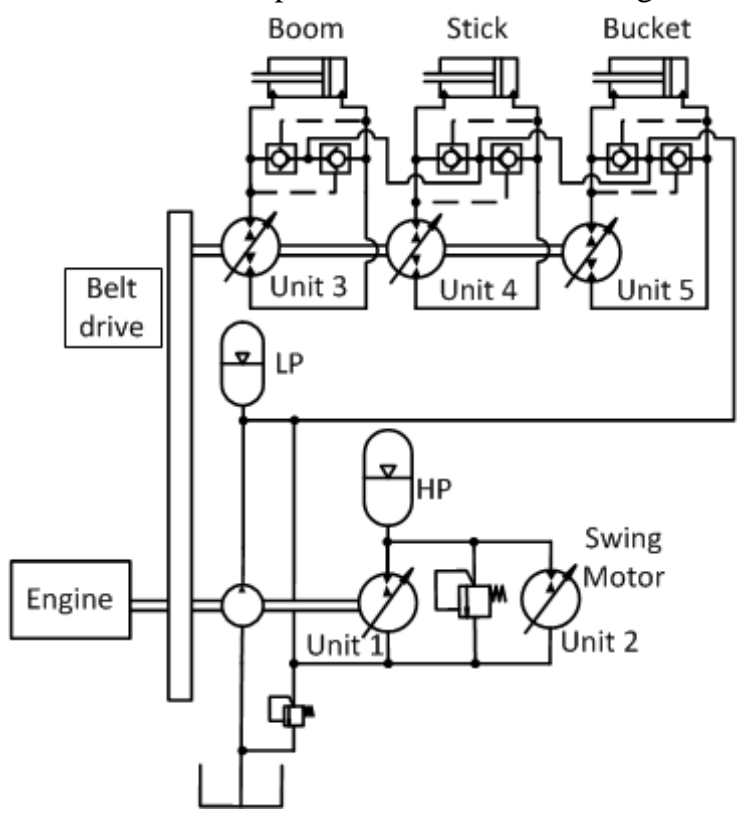

Figure 1.1 : DC S-P Hybrid Excavator

demonstrated previously in [6], for an aggressive, expertoperated truck-loading cycle, by using a conservative power management strategy that forces the downsized engine to operate at its maximum governed speed and maximum
DC prototype excavator in simulation. This was

power (near its maximum efficiency). Appropriate control of the primary unit (1) in the series-hybrid swing actuation system is necessary in order to allow charging of the accumulator with excess engine power and discharging the accumulator when power requested by the actuators is greater than the peak engine power.

In Section 2, the dynamic model that has been extensively used to simulate the dynamic behavior and fuel consumption of the DC S-P hybrid architecture will be briefly described. Further, an implementable power management strategy that exploits all available system degrees of freedom as well as achieving near-optimal behavior (in terms of replicating the optimal system state trajectories and control histories) is presented. This sheds light on what is possible with the DC $\mathrm{S}-\mathrm{P}$ hybrid architecture with reduced engine power, when used with the appropriate power management strategy.

The transition from the non-hybrid DC demonstrator machine to the DC S-P hybrid demonstrator machine has been completed and will be reported in this paper. Section 3 will outline the transition, with particular focus on the working hydraulic schematic and the controller in use for the excavator. Preliminary measurements on the excavator are presented in Section 4. Future work planned on the prototype hybrid excavator is also outlined.

\section{Simulation of the DC S-P Hybrid}

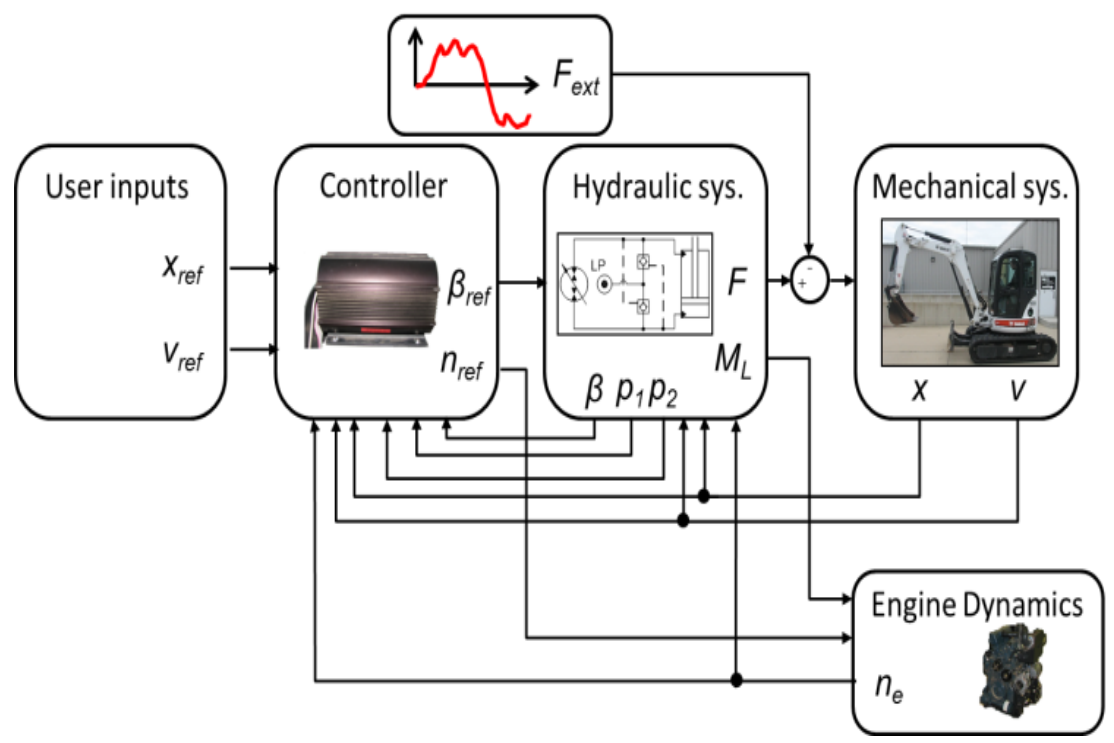

Figure 2.1: Simulation Model Structure

A co-simulation model (Figure 2.1) has been used to model the system dynamics, including both hydraulic and mechanical behavior, for both the non-hybrid and hybrid excavator architectures. The model accurately estimates energy and fuel consumption and was the basis for prediction of the fuel savings with the non-hybrid DC prototype. This model will be used to evaluate the energy consumption of the hybrid excavator as well, before measurements are made.
The simulation model is built to ensure tracking of a given excavator cycle, by providing inputs such as measured actuator positions $\left(x_{\text {ref }}\right)$ and loads $\left(F_{\text {ext }}\right)$. The user of the model must also input reference velocities, $v_{\text {ref, for the }}$ actuators (which are generated from measured joystick signals).

The first level of the 'Controller' in the simulation model is shown in Figure 2.2. Here, supervisory power management 
schemes are implemented. The outputs are commands for engine speed ( $\left.\underline{n}_{\mathrm{PM}, \mathrm{CE}}\right)$ and the various units, $\beta_{\mathrm{PM}, \mathrm{i}}$. These are interpreted as a speed command for the swing motor and flow commands for the DC actuators (boom, stick and bucket).

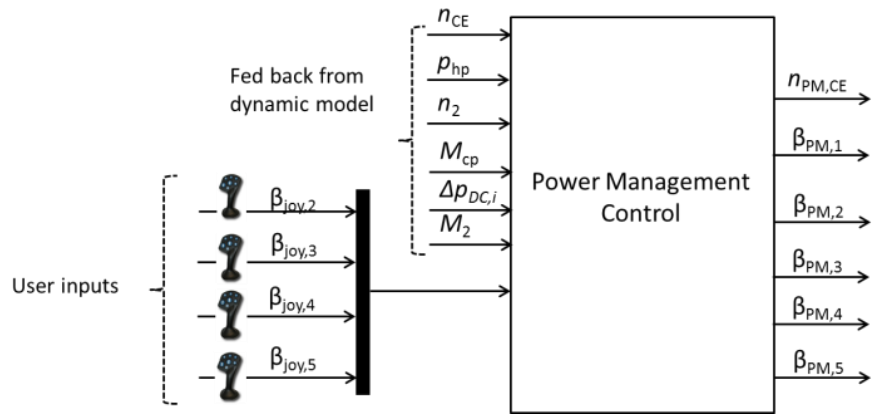

Figure 2.2 : Supervisory Level Power Management Control
For the linear actuators, these are processed in a feedforward manner ([9], not shown) by the low-level controller, together with a correction for transient pressure feedback. For the swing motor, the low-level control structure generates swash-plate commands based on error in speed of swing motor. The errors between the final unit displacement and engine speed commands (outputs of the lower-level controller) and the measured unit displacements and engine speed, are processed and sent as voltage commands to hardware, which is modeled in the 'hydraulic system' model, 'engine dynamics' and 'mechanical system' modules of the simulation model.

\subsection{Rule-Based 'Minimum-Speed' Power Management Strategy}

This implementable strategy was designed to replicate optimal state trajectories and control histories obtained from dynamic programming. From analysis of the optimal results for an expert truck-loading cycle (Fig. 2.3), it was found that for most part of the cycle, the engine stayed at minimum allowable speeds to meet flow requirements at the DC (linear) actuators.

\begin{tabular}{|c|c|c|}
\hline I. $P_{D C}<0$ & II. $P_{C E, \max } \geq P_{D C} \geq 0$ & III. $P_{C E, \max }<P_{D C}$ \\
\hline$n_{P M, C E}=n_{C E, \min }$ & $n_{P M, C E}=n_{C E, \min }$ & $n_{P M, C E}=n_{C E, \min }$ \\
\hline$P_{C E}=\min \left\{P_{\text {ref }}, M_{1} \omega_{C E+} P_{\text {load }}\right\}$ & $P_{C E}=P_{r e f}$ & $P_{C E}=P_{C E, \max }$ \\
\hline$M_{1}=M_{1, \max }$ & $M_{l}=\left(P_{C E}-P_{\text {load }}\right) / \omega_{C E}$ & $M_{1}=\left(P_{C E}-P_{\text {load }}\right) / \omega_{C E}$ \\
\hline
\end{tabular}

Table 2.1: Rules Used in Minimum-Speed Strategy

The terms, $P_{\mathrm{DC}}$ and $P_{\text {load }}$ - respectively, the total power requirement purely from DC units and the total power requirement from the engine shaft (DC power plus power required to accelerate engine) at any instant, are given by Eq. 2.1.

$$
\begin{aligned}
& P_{\text {load }}=\left(M_{D C}+\frac{I_{C E}\left(\omega_{C E, \text { min }}(k+1)-\omega_{C E}(k)\right)}{T_{s}}\right) \omega_{C E}(k) \\
& P_{\mathrm{DC}}(k)=M_{D C}(k) \omega_{C E}(k) \\
& M_{D C}(k)=M_{c p}(k)+i_{b e l t} \sum_{i=3}^{5}\left(\frac{\beta_{P M, i} V_{d, i} \Delta p_{i}}{2 \pi}+M_{s, i}\right)
\end{aligned}
$$

The engine was commanded to be at $n_{\mathrm{CE} \text {,min, }}$ the minimum allowable engine speed based on flow requirements at all instants in time (Eq. 2.2).

$$
n_{\mathrm{CE}, \min }=\min \left\{a b s\left[\frac{Q_{r e q, i}}{0.95 V_{d, i}}\right], i=3,4,5\right\}
$$

At moderate DC loads, the engine was kept at a reference power $P_{\text {ref }}(=18 \mathrm{~kW})$, which was in a high-efficiency area of the engine (but below the peak engine power), whereas for high loads above the peak engine power, the engine was kept at peak power $(20.7 \mathrm{~kW})$. For aiding loads $\left(P_{\mathrm{DC}}<0\right)$, unit 1 was kept at $100 \%$ to charge the accumulator up as fast as possible, whereas the engine was operated at a power which was the lower among the reference power or the power required to simply meet the total load as well as the storage pump torque. 
The rules presented in Table 2.1 replicate the optimal control results reasonably well, as can be seen from Figure 2.3.
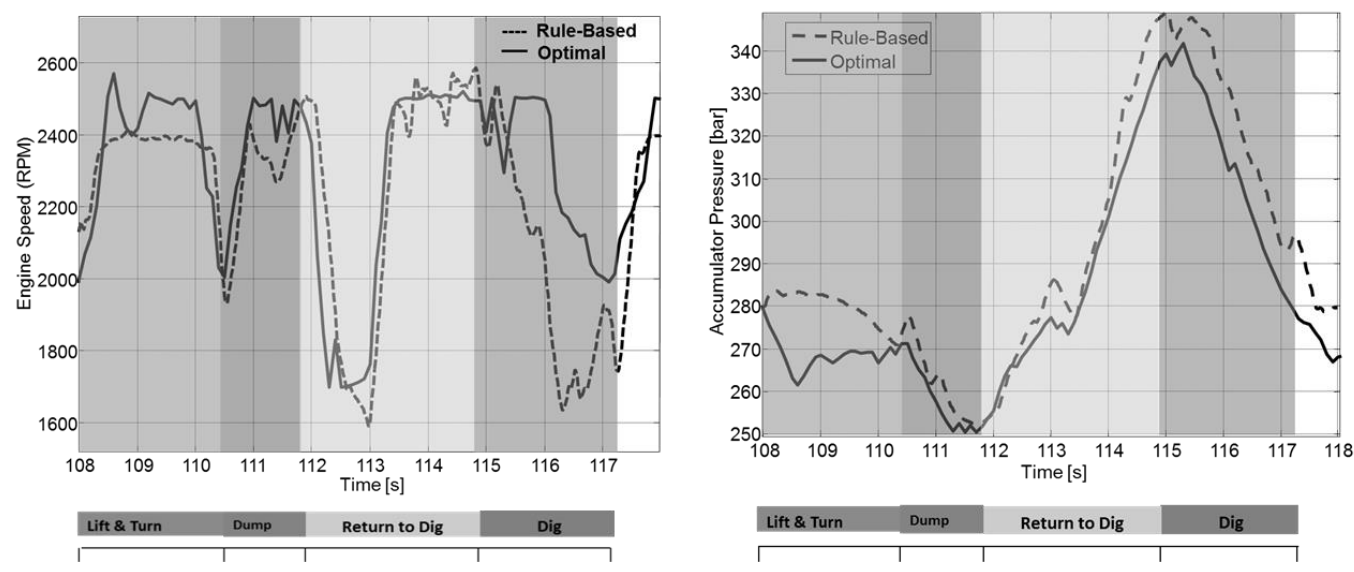

Figure 2.3: Replication of Optimal Accumulator Pressure and Engine Speed by Rule-Based Strategy

The accumulator steps in to meet peak actuator power requirements (where the engine could not meet them by itself, such as during the dig-phase or the 'dump' phase), and is charged during the 'return-to-dig phase', where the power requirement is moderate throughout and toward the end swing comes to rest and the boom is lowered (aiding DC load). The rule-base leads to slightly more aggressive charging of the accumulator than in the optimal case.

The controls, $\beta_{\mathrm{i}}, i=2,3,4,5$ are plotted in Figure 2.4. The DC pump displacements $(i=3,4,5)$ rise and fall with the corresponding flow requirements. There is a disagreement between the rule-based and optimal displacements in the digging phase - the rule-base enforces the engine speed to be at the minimum allowable speed (and thus both stick and bucket are at $100 \%$ ), whereas the optimal power management raises the engine speed a little and keeps the stick and bucket displacements just below $100 \%$.

The unit 2 displacement $\beta_{2}$, is adjusted to match the torque requirement at the swing motor and matches the optimal displacement reasonably well.
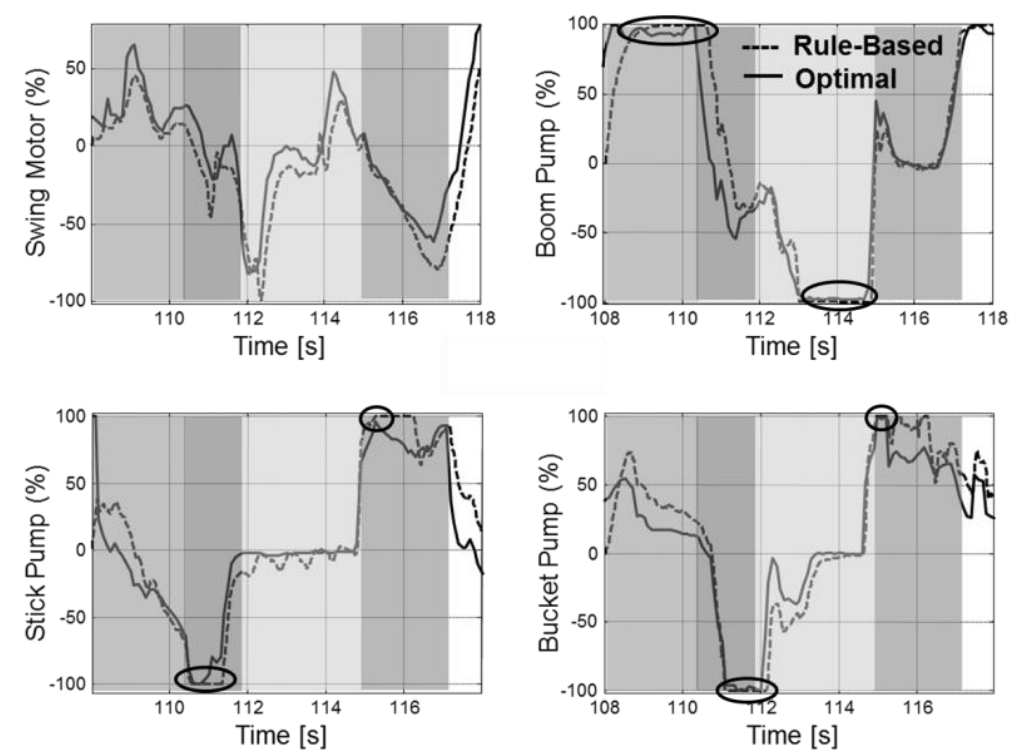

Figure 2.4: Replication of Optimal DC Pump and Unit 2 Displacements by Minimum-Speed Strategy

A comparison of the fuel consumption results is also provided between the DC non-hybrid with a constant speed strategy, and the DC hybrid, using both the minimum-speed strategy as well as the optimal power management results. 


\begin{tabular}{|c|c|c|c|}
\hline $\begin{array}{c}\text { Expert-Truck Loading } \\
\text { Cycle Results }\end{array}$ & $\begin{array}{c}\text { DC Non-Hybrid } \\
\text { (Constant Speed) }\end{array}$ & $\begin{array}{c}\text { DC Hybrid } \\
\text { (Min. Speed) }\end{array}$ & $\begin{array}{c}\text { DC Hybrid } \\
\text { (Optimal) }\end{array}$ \\
\hline Fuel Consumed (g) & 42 & 34.5 & 33.8 \\
\hline$\%$ Improvement & (Baseline) & $+17.9 \%$ & $+19.5 \%^{*}$ \\
\hline
\end{tabular}

Table 2.2 : Fuel Consumption Comparison

\section{DC S-P Hybrid Excavator Prototype}

The detailed circuit for the swing drive is explained in this section, including all the logic valves that are necessary for operation. The units 3, 4, 5 (Figure 1.1) are also shared by the auxiliary actuators (offset, left and right travel motors respectively), not shown here. Unit 1 is also used to provide flow to the blade.

\subsection{Series-Hybrid Swing Drive: Detailed Circuit Configurations}

Apart from the components shown in the simplified schematic of the DC S-P hybrid the detailed working hydraulic circuit of the series-hybrid swing drive is shown in Figure 3.1. There is an electrically-operated shut-off valve SF to isolate unit 2 from the accumulator as desired. An integrated safety block has also been added which contains - a manually-operated ball valve 'NO' that is always open (to connect accumulator to either of the units), another ball valve NC that is normally closed and used only to bleed off HP after operation, and a high-pressure relief valve RV HP. The two valves CV2 and ACV together perform the function of anti-cavitation of unit 2 when ACV is energized (during swing motor operation) and the function of loadholding (swing motor is stationary) when ACV is de-energized. The secondary controlled displacement unit (2) uses a high pressure swash plate control system.

The on-off valves A1, A2, B1 and B2 are responsible for switching unit 1 to provide flow either to the blade or to the serieshybrid swing drive. The pilot-operated check valves (PO CV-A, PO CV-B) are responsible for balancing flow when unit 1 is used for operation of the blade (which uses a differential cylinder), and the relief valves RV-A and RV-B limit pressures to acceptable levels.

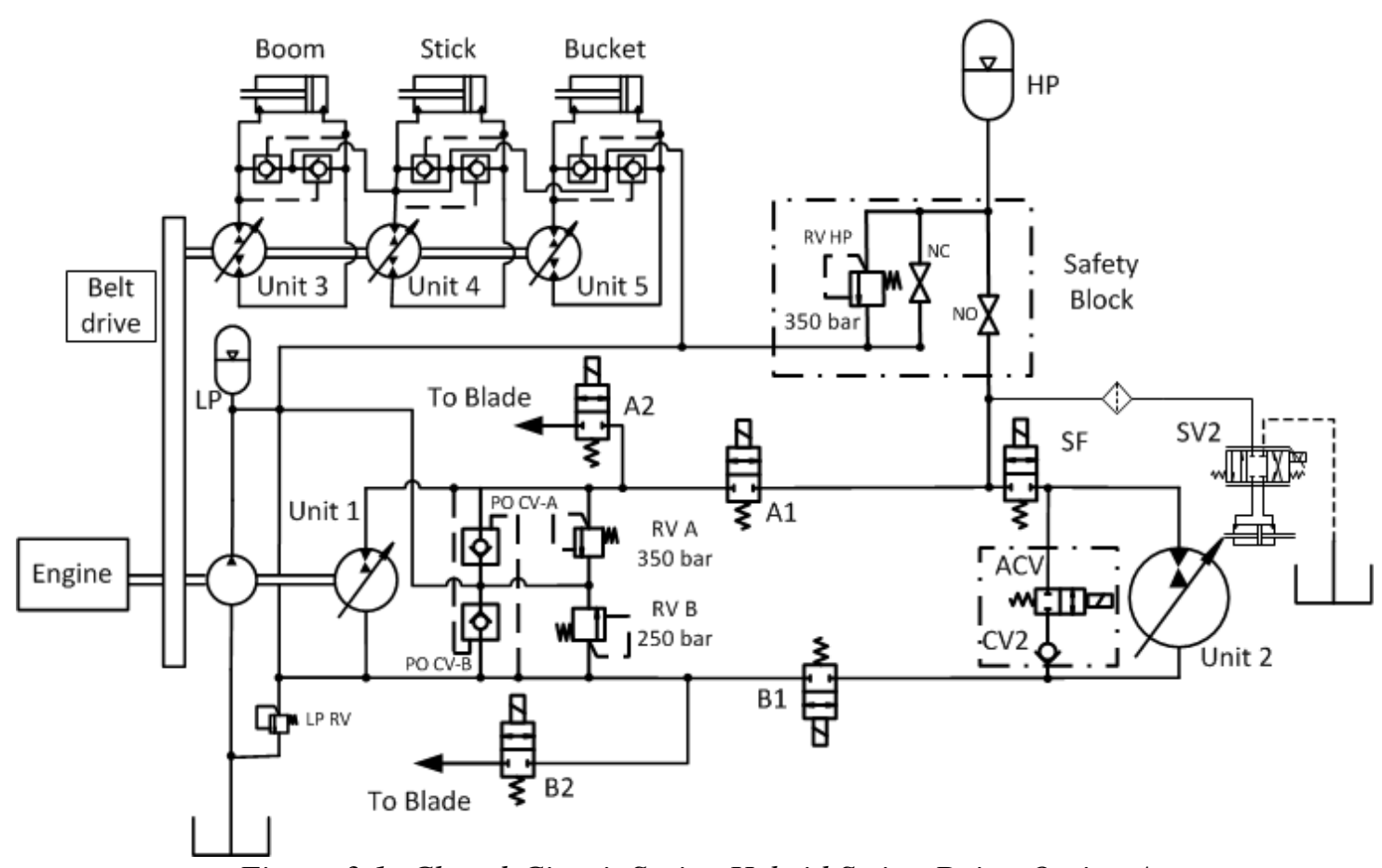

Figure 3.1: Closed-Circuit Series-Hybrid Swing Drive-Option A 
HP : high pressure accumulator

LP : low-pressure accumulator

Unit 'i': variable displacement, hydraulic unit ' $\mathrm{i}$ '

SF : Shut-off valve

PO CV-A : Pilot-operated check valves for A-side

$A 1, A 2, B 1, B 2$ : On-off valves (for function switching)

RV LP : low-pressure relief valve
RV A, RV B: Relief valves for unit 1

CV2 : Check valve (for anti-cavitation)

ACV : On-off valve (for anti-cav or load-holding)

SV2 : control valve for unit 2 swashplate adjustment

NO : normally open enabling valve

NC: normally closed bleed valve

RV HP : High pressure relief valve

Two different circuits are proposed here for the hybrid swing drive, although Option A (Figure 3.1) has been implemented on the prototype. They differ in their location of the shut-off valve SF. Option B allows that the high pressure accumulator HP can be isolated from either of the units allowing to switch operation of the swing actuator from secondary control to hydrostatic mode.

Open-circuit versions and versions without use of over-center motors (unit 2) of this architecture are also possible, although not shown here.

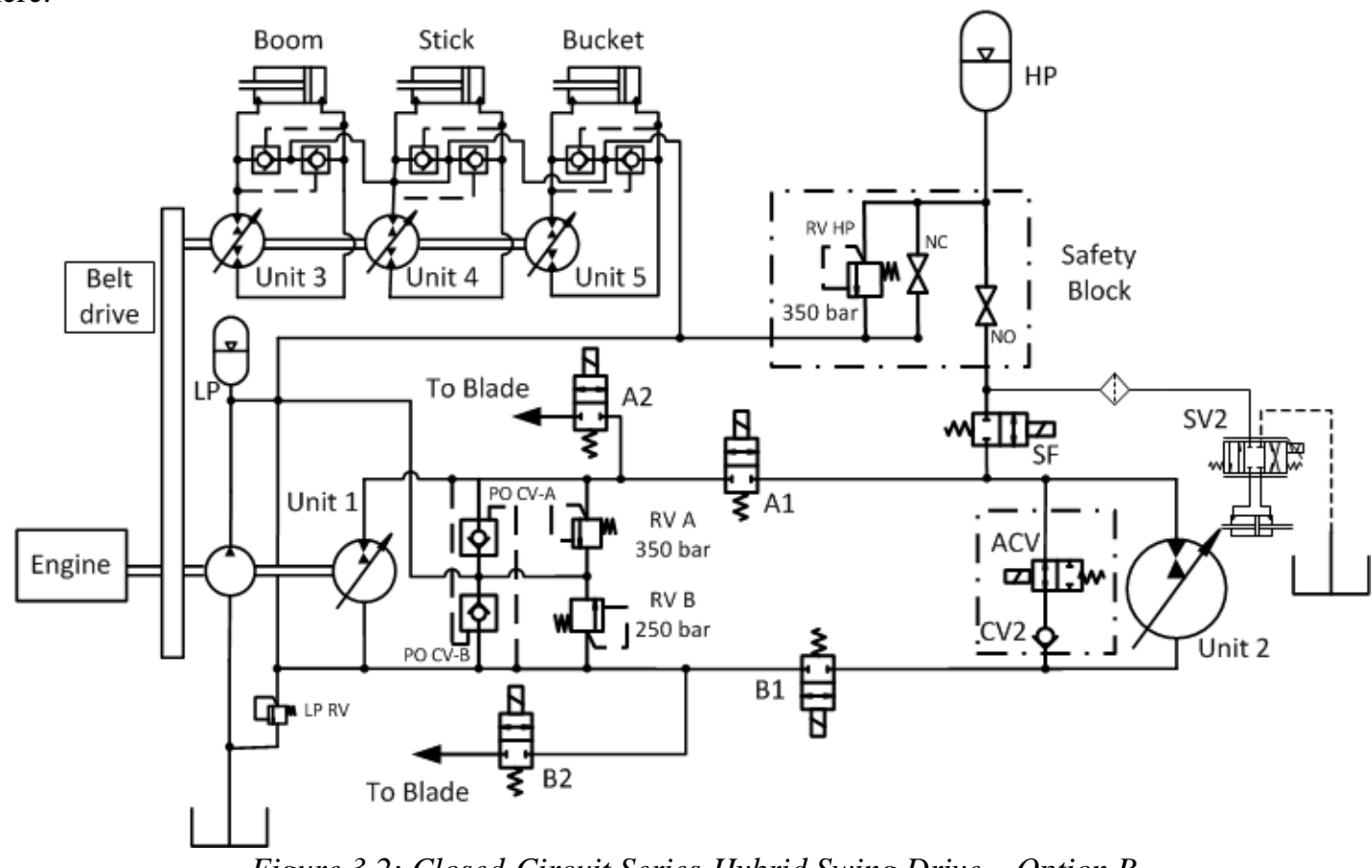

Figure 3.2: Closed-Circuit Series-Hybrid Swing Drive - Option B

\subsection{System Sizing \& Integration}

A study [10] evaluating various system designs (combinations of component sizes in the series-hybrid swing drive) on an even keel was performed previously. The sizing of the components on the prototype hybrid excavator was guided by this study, and components that were closest to these sizes were selected. The study ranked various designs according to their minimum fuel consumption (computed using dynamic programming) over an expert truck-loading cycle.

\begin{tabular}{|c|c|c|c|}
\hline$V_{\mathrm{i}}, i=1,3,4,5(\mathrm{cc} / \mathrm{rev})$ & $V_{2}(\mathrm{cc} / \mathrm{rev})$ & $V_{0}(\mathrm{~L})$ & $p_{0, \mathrm{hp}}(\mathrm{bar})$ \\
\hline 18.3 & 40 & 5.7 & 225 \\
\hline
\end{tabular}

Table 3.1: Component Sizes On Prototype Excavator

Thus each design was evaluated independent of power management. Available components that were closest in size to individual component sizes in the theoretically optimal design were chosen for integration on to the prototype.
Shown in Figure 3.3 are the main components necessary for transition from the DC prototype excavator to the S-P DC hybrid prototype. A 6 liter high pressure accumulator is used, rated to 350 bar. A 40cc variable displacement, overcenter swashplate type axial piston unit serves as the secondary controlled swing motor (unit 2). A new gearbox with an overall reduction ratio of 147.6 between the swing motor and cab, enables the new swing motor to operate at speeds between 0 to $1500 \mathrm{rpm}$. Previously, on the nonhybrid DC prototype excavator, a fixed displacement radial piston motor $(820 \mathrm{cc})$ was used, with a reduction ratio of 5.35 between motor and cab. 


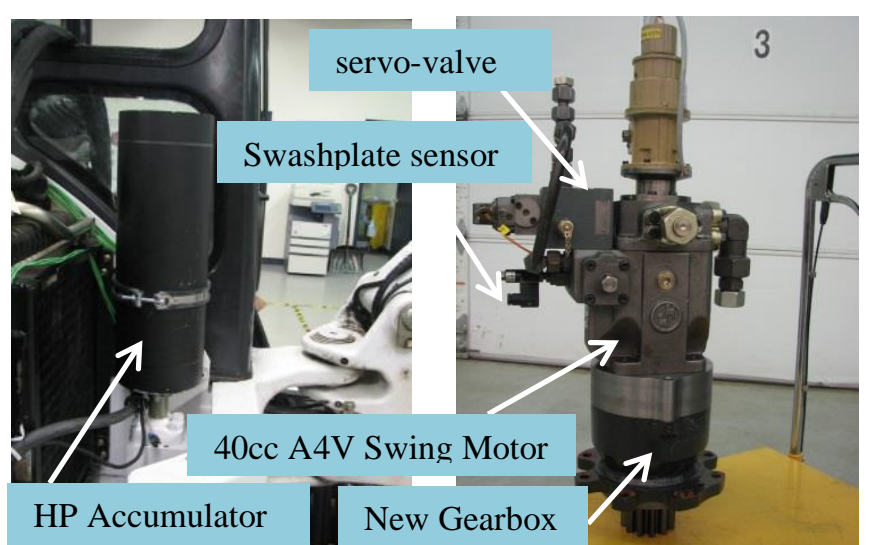

Figure 3.3: System Integration with Hybrid Components

The prototype excavator has been instrumented with appropriate sensors for motion control of the various actuators (Figure 3.4) and to advanced power management strategies.
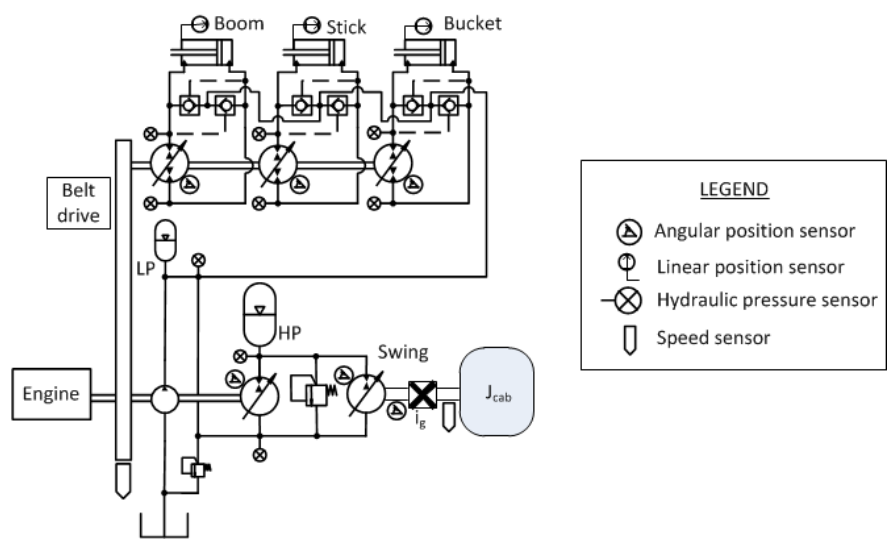

Figure 3.4: Sensors Instrumented on Prototype Excavator

Angle sensors are used to measure swashplate angles of all units. A rate gyroscope measuring cabin speed is used for

\subsection{Excavator Controller}

The overall structure of the excavator controller is summarized in Figure 3.5. The controller takes in the operator inputs (such as the joystick and lever positions), interprets them in terms of physical quantities (engines speed and \% displacement commands for the units) and also needs various measured quantities (pump displacements, accumulator pressure, engine speed, swing motor speed) as inputs. The final outputs of the controller are electrical signals (voltages or currents) that are directly applied to the hardware (servovalves in the swashplate control systems and engine actuator commands).

The swing motor is closed-loop speed-controlled, meaning that the joystick signal is interpreted as a speed command for the swing motor. The linear actuators (boom, stick and bucket and auxiliary functions) are open-loop, flow-controlled during motion meaning that respective joystick sginals are interpreted as flow commands (swashplate angle) for the corresponding unit $(3,4,5)$. Position control will be used to keep the actuators at rest when no motion is commanded. closed-loop speed-control of unit 2 during motion. A Halleffect angle sensor measuring unit 2 shaft position (converted online to cab position) is used for closed-loop (he cabin, when no motion is commanded with pressure sensors to measure HP and LP accumulat with pressure sensors to measure HP and LP accumulator pressures, as well as pressures at both ports of each unit (1, , 4 and 5 on the engine shaft. These are all diaphragm-type cylinders, and arear position sensors are integrated with the by the operator, to hold position. A linear motor (or 'engine speed actuator') that is directly linked to the diesel engine governor, is moved to change engine speed. A particular position of the linear actuator corresponds to a particular speed at which the governor cuts off fuel to the combustion chamber. Thus, an engine speed sensor and a position sensor for the engine speed actuator, are required to ensure speed control of the engine. Appropriate signal amplification hardware has also been incorporated to amplify controller output signals to the servo-valves (in swashplate control systems) and linear motor.

National Instruments' (NI) cRio control hardware is currently in use on the excavator to deploy the controller as well as for data acquisition. Controller development is done in Matlab Simulink and the NI Veristand software provides the user-interface for online controller tuning and signal monitoring. 


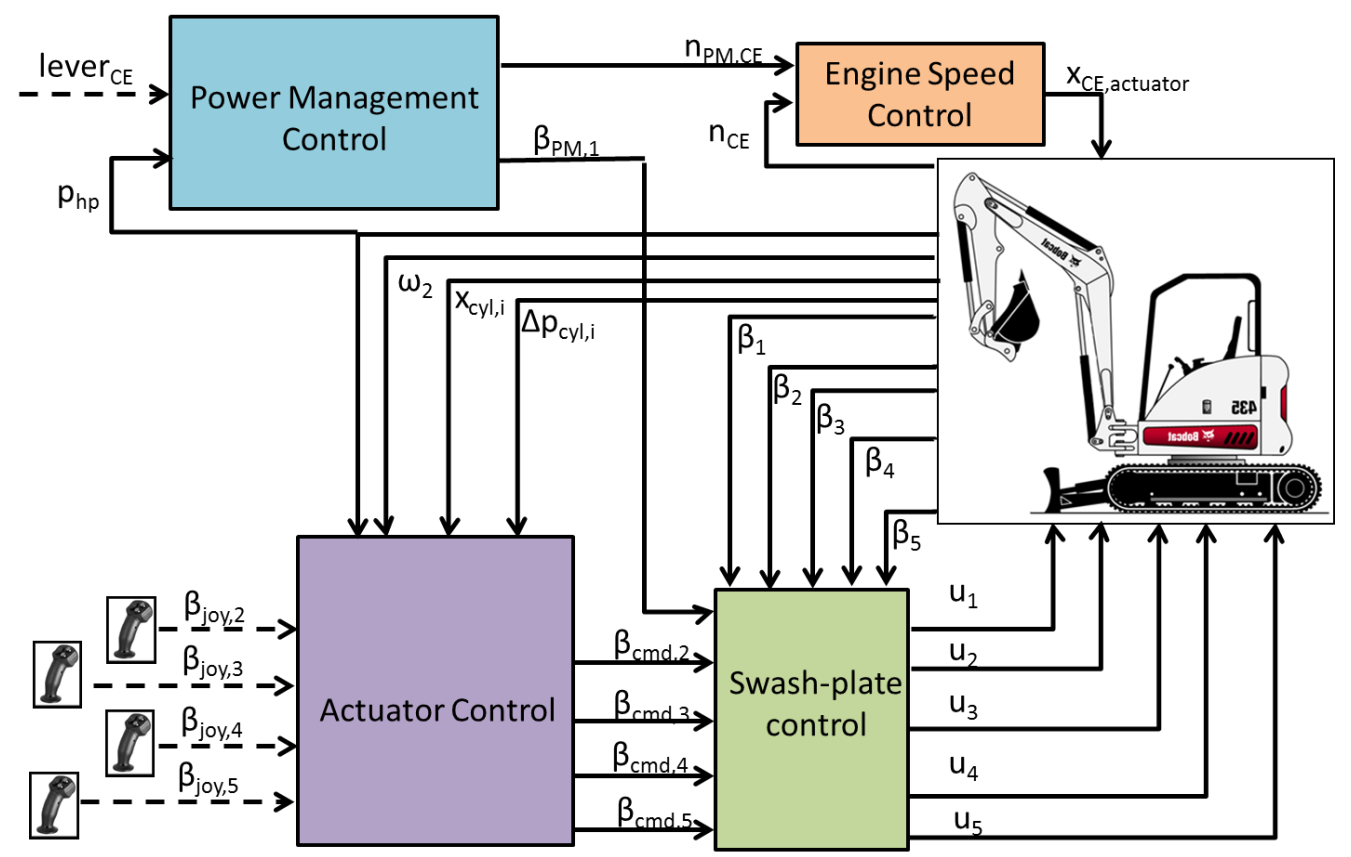

Figure 3.5: Structure of Controller on Prototype Excavator

The two controls, $\beta_{\mathrm{PM}, 1}$ (unit 1 displacement command) and engine speed $n_{\mathrm{CE}, \mathrm{cmd}}$ are determined by the power management routine. The other controls $\left(\beta_{\mathrm{cmd}, \mathrm{i}}, i=2,3,4,5\right)$ are manipulated to meet actuator requirements - i.e. $\beta_{\mathrm{cmd}, 2}$ should be high enough to swing motor torque requirement at the current accumulator (HP) pressure, and $\beta_{\mathrm{cmd}, 3}, \beta_{\mathrm{cmd}, 4}, \beta_{\mathrm{cmd}, 5}$ to meet cylinder velocity requirements at the current engine speed.

\subsubsection{Power Management Control}

In our first study which is reported in this paper, the engine is simply operated at a constant speed of $2500 \mathrm{rpm}$ (the maximum governed speed of this engine). Unit 1 is controlled in order to maintain a constant, desired accumulator pressure during operation - it is held at a constant value (40\%) when HP accumulator pressure is between 190 bar and 220 bar, and de-stroked close to zero as it nears 225 bar.

\subsubsection{Actuator Control}

The actuator controller is responsible for translating the various operator inputs to swashplate angle commands for the respective units $(2,3,4,5)$. As was explained before and evident from Figure 3.6, unit 2 (swing motor) is closed-loop speed controlled when motion is commanded and closed-loop position controlled when there is no joystick command. The joystick input is interpreted as a speed command when it is not zero.

When the operator commands motion, a combination of feed-forward and feedback control is used. A feed-forward term that accounts for accumulator pressure is also present, which computes the desired displacement required to meet a particular acceleration (using a nominal inertia term) at the measured accumulator pressure. This is added to a feedback term - which is the result of a PI controller acting on the error in speed. The sum of these two terms determines the final unit 2 displacement command, $\beta_{\mathrm{cmd}, 2}$.

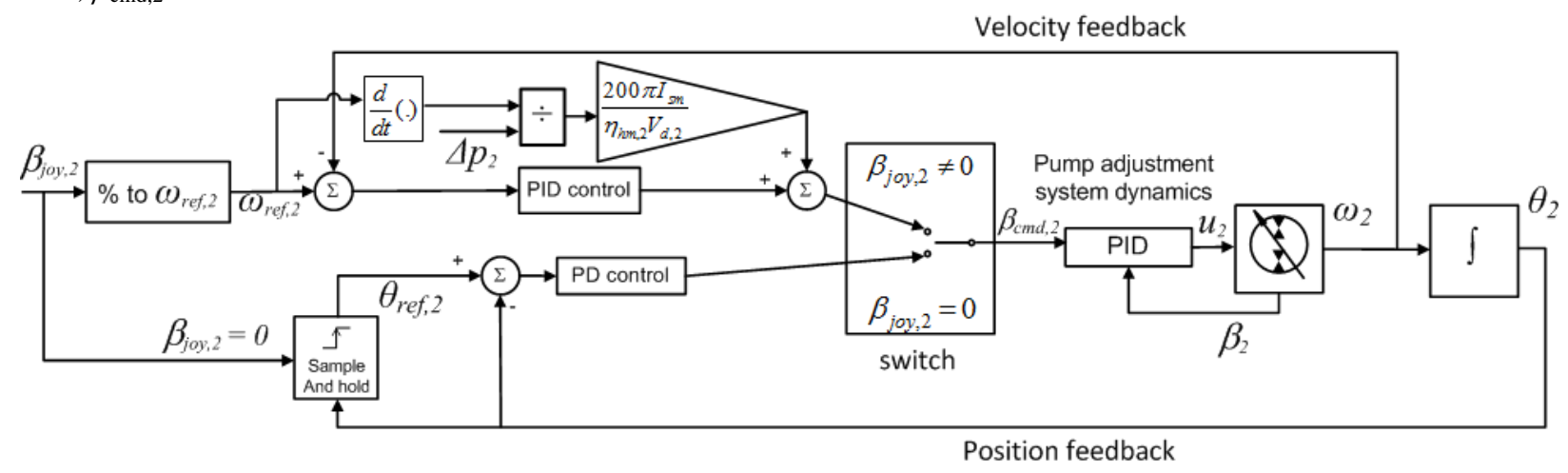

Figure 3.6: Actuator Control for Unit 2 
Figure 3.7 summarizes the results of simulation of the closed-loop speed control of the swing motor. The swing motor is commanded to follow speed profiles expected in a typical digging cycle in the first 10 seconds. The swing is at rest in the first 3 seconds (the 'dig' phase of the cycle), following which it accelerates gradually (and then cruises) toward the truck, from $t=3$ to $6.5 \mathrm{~s}$ (this phase is slow due to the high inertia of rotation due to an extended arm and a loaded bucket). Braking is fast and short (from $t=6.5 \mathrm{~s}$ to $\mathrm{t}=7 \mathrm{~s}$ ), followed by a short phase at rest wherein the bucket is emptied in the truck. Following this, the cab accelerates rapidly back toward the digging trench (from $t=7.2 \mathrm{~s}$ to $\mathrm{t}=8.1 \mathrm{~s}$ ), cruises at maximum speed and brakes (slower compared to braking before emptying of accumulator). It can be seen that the simulated swing motor speed follows the commanded swing motor speed very well throughout the first 10 seconds.

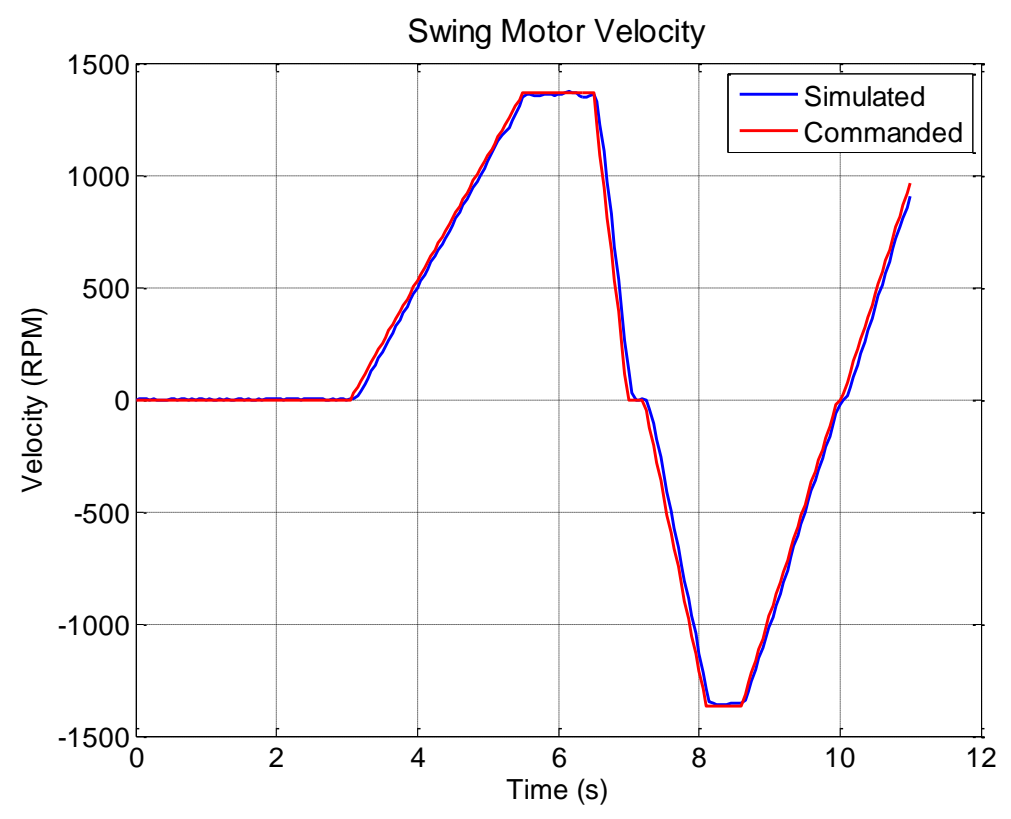

Figure 3.7: Simulated Results of Swing Motor Closed-Loop Speed Control

When the boom, stick or bucket are to be moved, they are done so in an open-loop or flow-controlled manner (Figure 3.8). The joystick command translates directly to a swashplate command (with some regulation using pressure-feedback to avoid uncommanded actuator oscillations) for the corresponding unit. There is no velocity or position feedback, during motion. Once the joystick is centered, it is desired that the corresponding actuator hold its position.

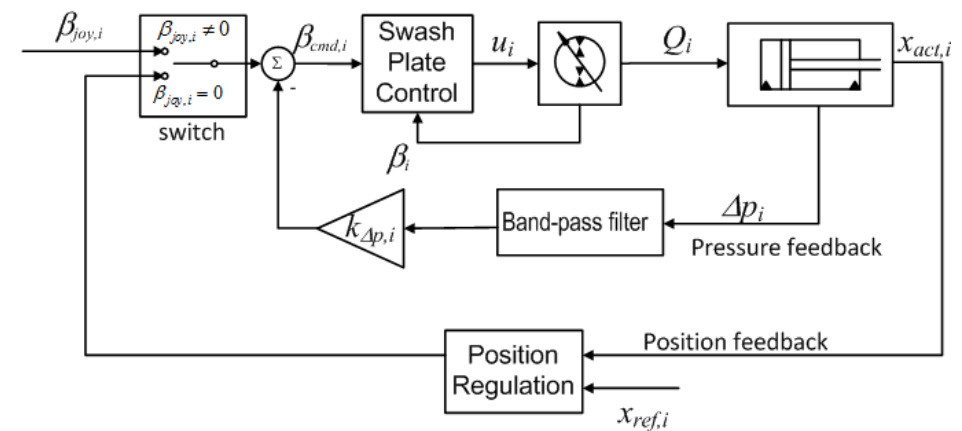

Figure 3.8: Actuator Control for DC Units (supplying boom, stick, bucket)

The position controller currently being used for all linear actuators (when no motion is commanded) is the limited semiintegrator (Berg, 1999). The velocity control for the swing motor is simply a PID controller at this stage, although a more sophisticated controller will be required once better power management strategies are implemented (accumulator pressure will not be constant).

\subsubsection{Unit Displacement Control}

Swash-plate commands $\left(\beta_{\mathrm{cmd}, \mathrm{i}}, i=1,2,3,4,5\right)$ from the actuator controller are inputs to the swashplate controller. The swashplate controller acts on the error between the commanded and measured displacements, to provide an output current or voltage signal for the servo-valve. These are the final outputs of the excavator controller. PI controllers are used as the swashplate control law. 
Discrete PI controllers are also used for the engine controller, which generates a command for the linear motor (or engine speed actuator) based on the error in commanded and actual engine speeds. An aspect of the excavator controller that has not been shown here is the anti-stall controller. Here the displacement commands for the units on the engine shaft $(1,3,4,5)$ are reduced if the engine speed is significantly below the engine speed command.

\section{Preliminary Measurements on Prototype}

A video of the prototype hybrid DC excavator being operated in a 90-degree digging cycle (Fig. 4.1) can be found at the following website: https://engineering.purdue.edu/Maha/ccefp/.

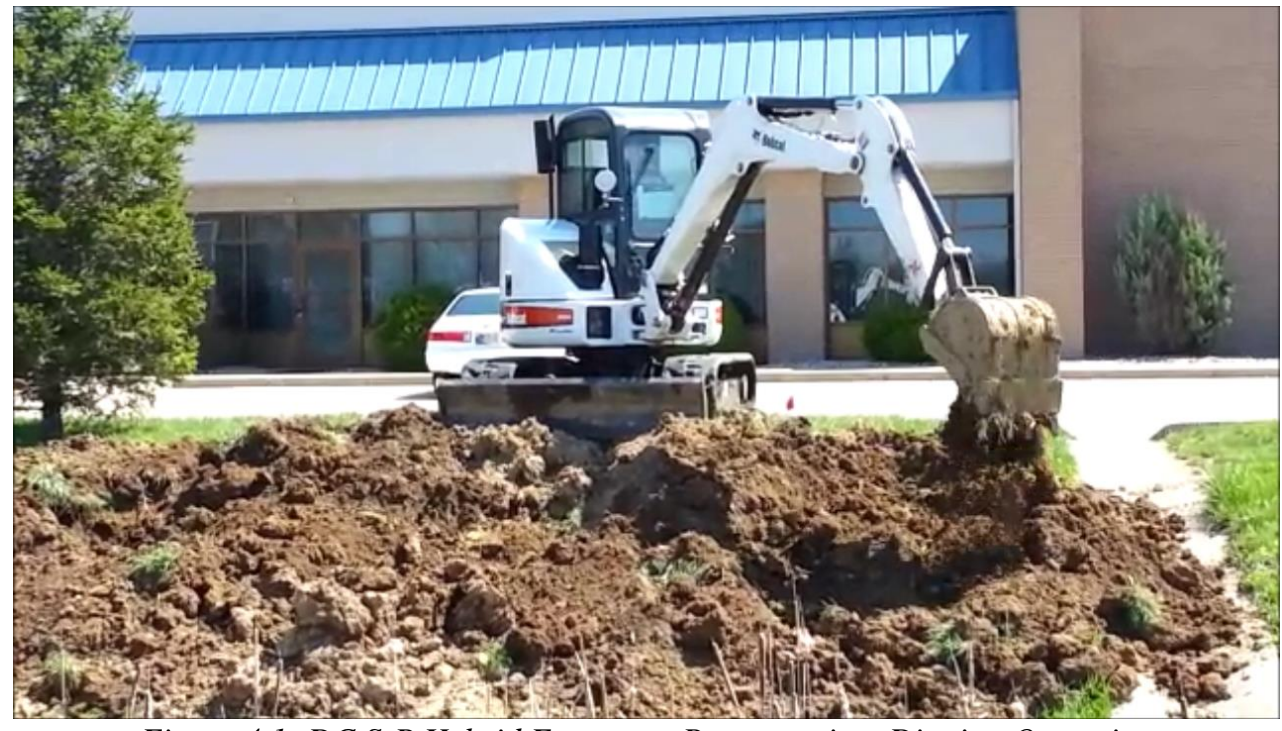

Figure 4.1: DC S-P Hybrid Excavator Prototype in a Digging Operation

Measurement results during an artificial digging maneuver (about two scoops or cycles) are plotted in Figure 4.2, Figure 4.3 and Figure 4.4. In Figure 4.2, commanded and measured pump displacement (\%) are plotted. These plots show the effectiveness of the pump displacement controller being used.
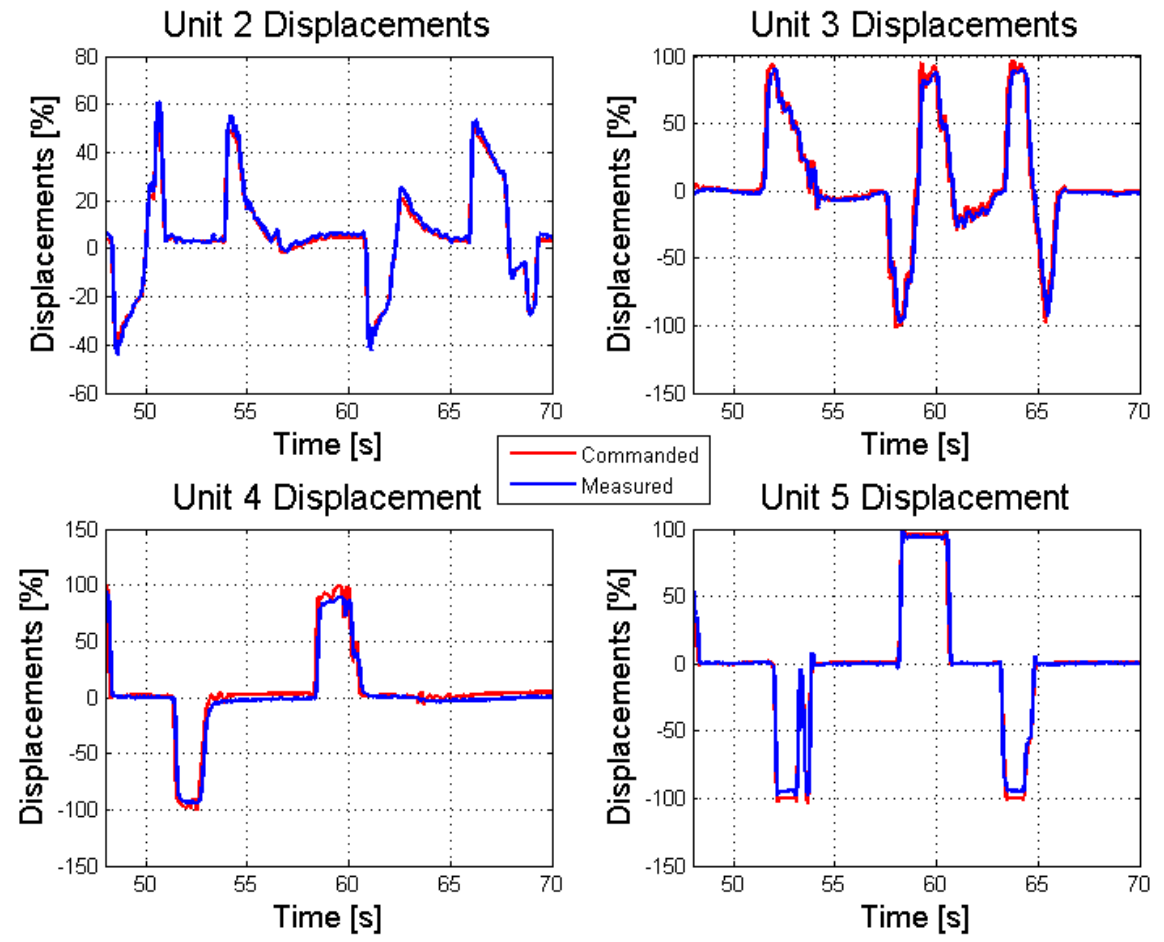

Figure 4.2: Unit Swashplate Angle Commands and Measurements during Artificial Dig Maneuver 
Analyzed together with Figure 4.3, it can be seen that a change in the position of the actuators (boom, stick and bucket only) occurs when the displacements of the corresponding units are non-zero. Also, the actuator positions (especially the boom) do not change in an exactly cyclical fashion since this artificial dig cycle was performed by a novice operator.
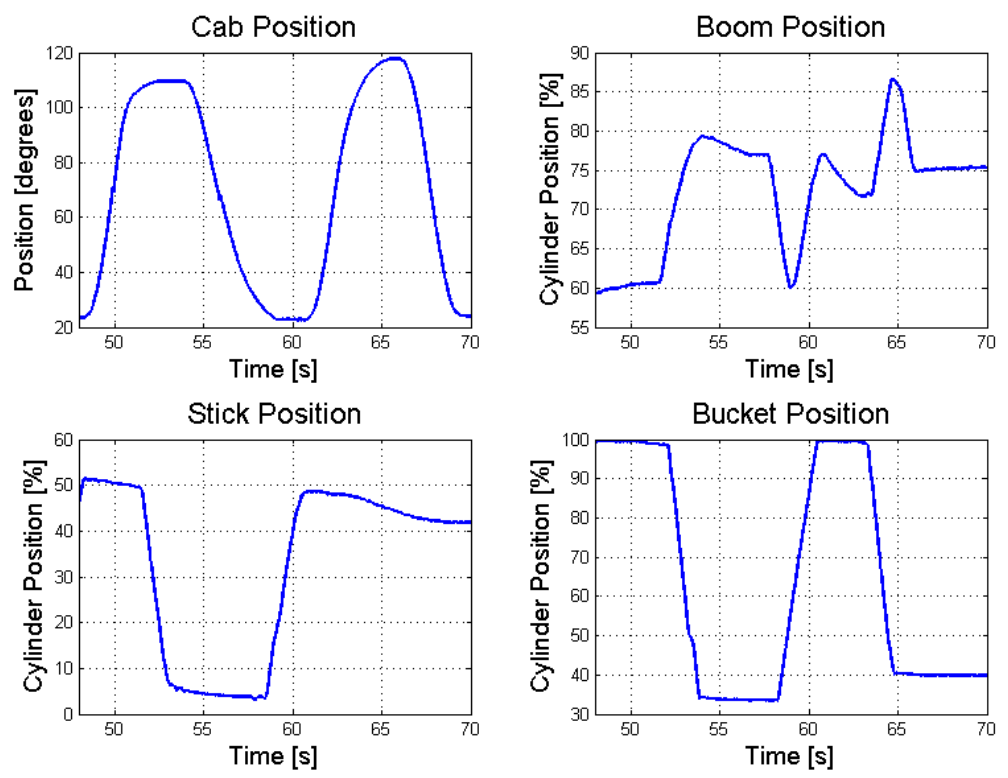

Figure 4.3: Actuator Positions during Artificial Dig Maneuver

Engine speed and pressure (of the accumulator HP) are plotted in Figure 4.4. The engine speed is commanded to stay near $1900 \mathrm{rpm}$ while unit 1 is commanded to ensure that the accumulator pressure stays at 225 bar. It can be seen that when the cabin accelerates, HP is drained slightly (to 220 bar) from $t=48$ s to 50 s, whereas during deceleration of the swing (from $t=$ $50 \mathrm{~s}$ to $52 \mathrm{~s})$, there is a slight increase in accumulator pressure above 225 bar. Once at rest ( $\mathrm{t}=52 \mathrm{~s}$ to $54 \mathrm{~s})$ the pressure drops back to 225 bar.
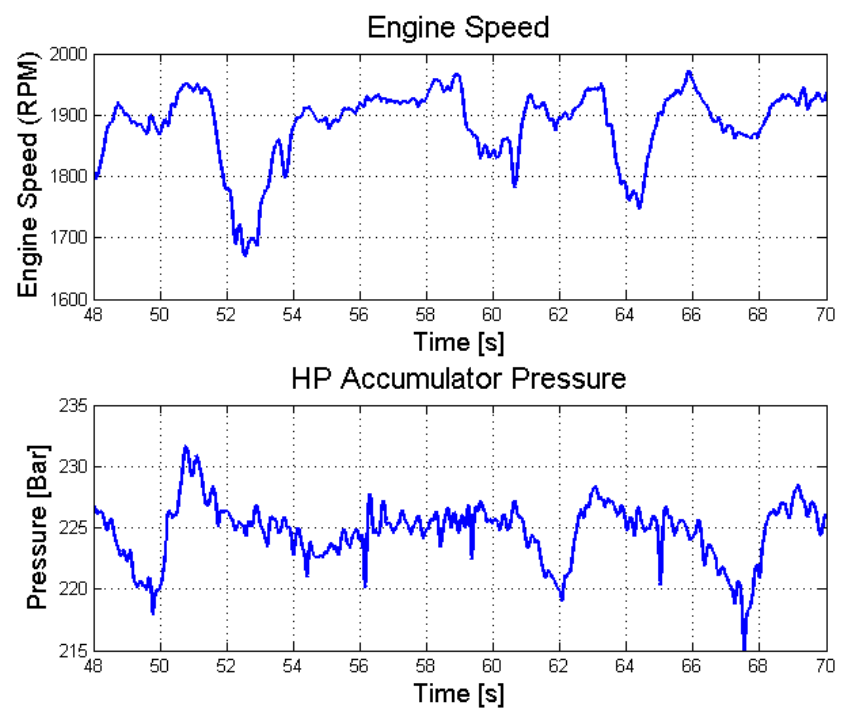

Figure 4.4: Engine Speed and Accumulator Pressure During Artificial Dig Maneuver (with Preliminary Power Management)

\section{Conclusions and Future Work}

A prototype DC S-P hybrid excavator has been realized at the Maha Fluid Power Research Center at Purdue University and instrumented with electronic equipment necessary for implementation of actuator motion control and advanced power management schemes. Closed-loop speed control has been demonstrated for the secondary-controlled swing motor on the prototype, and working open-loop flow control demonstrated for the other actuators as well.

Based on a high-fidelity dynamic co-simulation model, the novel hydraulic hybrid architecture is predicted to have substantially higher energy efficiency than state-of-the-art valve-controlled excavators, as well as to show a significant improvement over the non-hybrid prototype DC excavator, 
while enabling up to $50 \%$ engine downsizing. The simulation model has also been utilized to demonstrate the ability of a rule-based power management strategy to replicate optimal control results.

In the future, the single-point power management strategy ([4], [6]) will be implemented on the excavator to demonstrate the feasibility of using reduced engine power and productivity measurements will be made for an expert truck-loading cycle. Just as in the case of the non-hybrid DC prototype, these will be made following system simulations of the DC S-P hybrid concept (actual engine downsizing is not planned on the prototype). Implementation of advanced power management strategies will also be performed, to investigate power management schemes that yield nearoptimal results independent of duty cycle.

\section{Nomenclature}

\begin{tabular}{|l|l|l|}
\hline Designation & Denotation & Unit \\
\hline$\beta_{\mathrm{joy}, \mathrm{i}}$ & $i^{\text {th }}$ joystick command & $(\%)$ \\
\hline$\beta_{\mathrm{PM}, \mathrm{i}}$ & displacement command for $i^{\text {th }}$ unit & $(\%)$ \\
\hline$\beta_{\mathrm{i}}$ & measured displacement of $i^{\text {th }}$ unit & $(\%)$ \\
\hline$n_{\mathrm{CE}}$ & Engine speed & {$[\mathrm{rpm}]$} \\
\hline$n_{\mathrm{CE}, \mathrm{cmd}}$ & Commanded engine speed & {$[\mathrm{rpm}]$} \\
\hline$n_{\mathrm{i}}$ & Speed of $i^{\text {th }}$ hydraulic unit & {$[\mathrm{rpm}]$} \\
\hline$\Delta p_{\mathrm{i}}$ & Pressure difference across $i^{\text {th }}$ unit & {$[\mathrm{bar}]$} \\
\hline$M_{1, \mathrm{des}}$ & Storage pump torque & {$[\mathrm{N} . \mathrm{m}]$} \\
\hline$M_{\mathrm{cp}}$ & Charge pump torque & {$[\mathrm{N} . \mathrm{m}]$} \\
\hline$M_{\mathrm{des}}$ & Desired engine output torque & {$[\mathrm{N} . \mathrm{m}]$} \\
\hline$V_{\mathrm{d}, \mathrm{i}}$ & Displacement of $i^{\text {th }}$ hydraulic unit & {$[\mathrm{cc} / \mathrm{rev}]$} \\
\hline
\end{tabular}

\section{References}

[1] Rahmfeld, R. and Ivantysynova, M. 2001. Displacement Controlled Linear Actuator with Differential Cylinder A Way to Save Primary Energy in Mobile Machines. Proc. of 5th International Conference on Fluid Power Transmission and Control (ICFP'2001), Hangzhou, China, pp. 316 - 322.

[2] Zimmerman, J., Pelosi, M., Williamson, C., and Ivantysynova, M. 2007. Energy Consumption of an LS Excavator Hydraulic System.2007 ASME International Mechanical Engineering Congress and Exposition, Seattle, WA, USA. IMECE2007-42267.

[3] Williamson, C., Zimmerman, J. and Ivantysynova, M. 2008. Efficiency Study of an Excavator Hydraulic System Based on Displacement-Controlled Actuators. Bath ASME Symposium on Fluid Power and Motion Control (FPMC2008), pp.291-307
[4] Williamson, Christopher A. Ph.D. Thesis, Purdue University. December 2010. Power Management for Multi-Actuator Mobile Machines with Displacement Controlled Hydraulic Actuators.

[5] Zimmerman, J., Busquets, E. and Ivantysynova, M. 2011. 40\% Fuel Savings by Displacement Control Leads to Lower Working Temperatures - A Simulation Study and Measurements. Proceedings of the 52nd National Conference on Fluid Power 2011, NCFP I1127.2.

[6] Zimmerman, J. and Ivantysynova, M. 2011. Hybrid Displacement Controlled Multi-Actuator Hydraulic Systems. Proceedings of the 12th Scandinavian International Conference on Fluid Power, May 18-20 2011, Tampere, Finland, pp 217 - 233.

[7] Zimmerman, J., Hippalgaonkar, R. and Ivantysynova, M. 2011. Optimal Control for the Series-Parallel Displacement Controlled Hybrid Excavator.ASME/Bath Symposium on Fluid Power and Motion Control, Arlington, VI, USA.

[8] Hippalgaonkar, R., Zimmerman, J. and Ivantysynova, M. 2011. Investigation of Power Management Strategies for a Multi-Actuator Hydraulic Hybrid Machine System. SAE 2011 Commercial Vehicle Engineering Congress, Rosemont, IL, USA.

[9] Hippalgaonkar, R., Ivantysynova, M. and Zimmerman, J. 2012. Fuel-Savings of a Mini-Excavator through a Hydraulic Hybrid Displacement Controlled System. $8^{\text {th }}$ International Fluid Power Conference (IFK) Dresden. Dresden, Germany.

[10] Zimmerman, Joshua D. Ph.D., Purdue University, May 2012. Toward Optimal Multi-Actuator Displacement Controlled Mobile Hydraulic Systems. 